\title{
CELEBRITIES IN A CHANGING WORLD: A CRITICAL VIEW FROM THE VIETNAMESE CONTEXT
}

\author{
Phan Quang Anh* \\ Department of Communications and New Media, \\ National University of Singapore, Blk AS6, \\ \#03-41, 11 Computing Drive, Singapore 117416 \\ E-mail: phanquanganh@u.nus.edu
}

Published online: 15 January 2019

To cite this article: Phan, Q. A. 2019. Celebrities in a changing world: A critical view from the Vietnamese context. International Journal of Asia Pacific Studies 15 (1): 133-151, https://doi.org/10.21315/ijaps2019.15.1.5

To link to this article: https://doi.org/10.21315/ijaps2019.15.1.5

\begin{abstract}
This paper aims to provide an analysis of the concept Celebrity set in the context of Vietnam under the influence of globalisation. By using theoretical ideas of Cultural and Critical Studies to dissect how celebrities, especially foreign wellknown personas, have been brought into the attention of Vietnamese audiences and how their images impact the everyday life of a developing yet communist country. The acceptance attitude has been going along with the apparent doubt about the possibility of causing cultural homogenisation, which seems to be a threat at the surface level rather than a critical one. Finally, a concept model to help provide an overview of the notion Celebrity is also presented. That tentative model tries to explain the way celebrities are perceived and how we should understand their role in the quotidian life through a critical lens.
\end{abstract}

Keywords: Celebrity, Vietnam, globalisation, media, cultural studies

\section{INTRODUCTION}

In her erudite review of Vietnamese television programmes and the role of celebrities, Nguyen (2011) believed that when we touch upon the celebrities as a social phenomenon that is worth dissecting, one of the most impressive and well-quoted definitions of this term belongs to Daniel Boorstin (1982: 49): "a celebrity is a person who is known for his well-knownness." 
Since 1962, Daniel Boorstin has made this statement become a "characteristic of this culture" (the American context, to be specific) in the modern age, compared to which the way that Greek gods received their glorious time "in the sixth century BC" could be considered a prototype (1982: 49). The fame and the reputation-making process based on mass media have been studied for decades in countries where mass media has gained a significant development. In Asia, viewpoints and comments on this phenomenon almost automatically fall into a binary discussion between elite culture and popular culture in which the celebrity is often perceived as a low ranked topic. At the same time, celebrity and related contents, which are seen as a media focus, are also considered a sign of deterioration in general aesthetic and social ethics (Nguyen 2011). This angle, looking from the Confucianism's viewpoint of East Asian countries where moral values are treasured, is actually convincing. But it would be inadequate unless we examine this issue more broadly and deeply.

In the English language, there is a relative difference found in the context that the two words Star and Celebrity are used when we make an excavation to look for the origin of the fame. John Hartley (2002: 26) suggested that:

The concept of celebrity differs from that of the star, in that the latter is understood as being a product of a particular medium, the Hollywood film industry. Celebrity, in comparison, is understood to have arisen under the conditions of postmodernity whereby the hyper-production of images leads to some faces and bodies being more recognisable than others.

Nonetheless, if we presume that both Star and Celebrity are claimed as the favourite children of the mass media in order to bring a visual satisfaction to the majority, then these two subjects could share the same attention paid by media studies researchers.

Daniel Boorstin, in another perspective, gave out a distinguished separation between Hero and Celebrity by analysing their ways to achieve the glory. According to Boorstin (1982: 61), the celebrity could be considered an invention for the purpose of satisfying the exaggerated expectation of human about the greatness, while the hero is admired by actually achieving his greatness. It could be unfair if we assert that celebrities do not have guts but still receive the glory. In fact, in the pre-media period, the hero has to build up his good reputation by himself or by the oral transmission using resonant sounds of his achievements - myths, legends or tales. His daily life does not become a topic on the streets as his sacred reputation, morally, does not allow a person to whisper about it. For the case of celebrity in the modern age, 
Boorstin (1982: 61) stated that "The Hero created himself while Celebrity has been created by the media."

If the formation of the hero's portrait achieved through the retrospective of their achievements, the tectonic process of creating the reputation for a celebrity only begins when the media changes concerns from his professional activities (in other words, their achievements and dedications) to his private life. A movie actor/actress only becomes a Star when the audiences could see that their real life is more interesting than their roles. Slowly but steadily, his reputation given birth by his own life will outlive the audience's memory about his demonstration. The celebrity in this context would be grasped as an open discourse - the "systems of thoughts composed of ideas, attitudes, courses of action, beliefs and practices that systematically construct the subjects and the worlds of which they speak" (Lessa 2006: 285). In this discourse, Nguyen (2011) thought that socio-cultural impulses continuously negotiate to "create definitions for the phenomenon, image and identity." During that negotiation process, a sequence of rhetorical questions would be posted which aims to demythologise the celebrities: Are they truly special or just like us? Is their reputation temporary or natural and consistent? They deserve to gain the "dazzling light" or it is only a sign of being lucky for a while? Are they really talent or only a "flawless fake"? All these inquiries make the audience stand between the two worlds - a mental dilemma as described by Jean Baudrillard (2010: 81): "One both believes and does not."

As a matter of fact, although it is hard to deny that the reputationbuilding process made by mass media is not a fairly typical example of the dumbing down process (Nguyen 2011) (worded in another way, it is about the usual availability of the sensational news instead of the formal information such as politics, social activities, etc.), it deserves to be sophisticatedly analysed considering the popularity, social impacts and the complexity of this phenomenon, which completely fits the critical theory perspective employed in cultural studies' research. Study of media is grasped as an innovative interdisciplinary domain of research that deals with the ways in which culture creates, shapes out or transforms individual experiences, various aspects of everyday life, social relations and their impacts, and power (Sardar and Van Loon 1994). Within the scale of this paper, using concepts of cultural studies is a way to find out how people understand and perceive the celebrities, how strangers with fame impact the individuals' life, which roles that they play, and which social functions that famous people are capable of; all are set within the context of globalisation. Given that those questions are broad and need to be concisely answered, Vietnam will be chosen as the case study in order to comprehend how the Celebrity concept influences a communist society. 


\section{GLOBALISATION AND THE QUESTION ON CULTURAL HOMOGENISATION}

It was not by accident that globalisation was given birth as one of the kernels conceived by social sciences and humanities, on which the idea of its influence to culture has been focused and emphasised. As mentioned by Tran Huu Dung (2005), the story of globalisation has become "a usual favourite topic of contemporary western scholars" as well as "an issue which is worthy to be paid attention" from non-western countries (Vietnam, China or North Korea, to be specific) where national and cultural identities are considered "the emblem of the whole nation." This emblem, indeed, must be understood as a metaphor to define their respectful historical tradition with which, globalisation, going abreast with its affection to culture has made their chronicle become vulnerable when it has to face the enquiry of cultural homogenisation. On the one hand, the introduction of foreign celebrities through various media channels has shown a positive perception from those countries, proving that they somehow accept to step in the globalisation procedure in terms of culture. However, on the other hand, communist countries are likely afraid of the fact that the excessive presence of these celebrities could either damage indigenous cultural values or reassure the role of capitalism, from which the enquiry on cultural homogenisation arises. In the case of Vietnam, Nguyen (2007) noted that preserving national culture identity (along with another one which was National-Scientific-Popular) has been known as the most used political motto in Vietnam for years that has been utilised to embed in the management principles applied to culture-related fields. Although Vietnam early got in touch with Chinese, French, Russian and American culture, and has been more active since its participation in UNESCO, Tran et al. (1998) asserted that the role played by Vietnam during those cultural exchange processes in the past was inherently and primarily of a colony and/or a subject that served for political purposes. Reid (2010) claimed that we can find various types of nationalism in Southeast Asia ranging from ethnics-based to outrage-at-State; in the case of communist countries like Vietnam, Rausch (2011) commented that there is a strong bond between nationalism and communism, with which the concept of preserving national identity is highlighted as a way to protect the ruling ideology. Nonetheless, as globalisation and integration have emerged as the new tendency that Vietnam wants to pursue, that extreme nationalistic view seems to be compromised as xeno-factors in cultural activities are no longer uncommon. 
The trickiest yet still controversial task is how to approach the definition of Culture, Globalisation and Homogenisation as these three terms are still main objects of continuous debates. The term culture, for instance, defies precise definition due to its complexity, variability and elusiveness. Already in the 1950s, when Kroeber and Kluckhohn published their review of the issue, the word Culture had at least 150 known definitions (Kroeber and Kluckhohn 1952). Since that time, the term has been redefined many times over, suggesting to us that we are entering a vast epistemological space. Setting the idea of Culture in the reciprocal relationship with Globalisation, Held et al. (1999: 329) asserted that we should perceive culture as "a lived and creative experience for individuals as well as a body of artefacts, texts and objects." This viewpoint, obviously, could be seen as a derivative and narrowed reception of the idea stated by E. B. Tylor in 1871 as Culture should be grasped as a "complex whole which includes knowledge, belief, art, morals, law, custom, and any other capabilities and habits acquired by man as a member of society" (cited by Griswold 1994: 8). However, the definition given by David Held is adequate as he merged it with the context of Globalisation-a "movement of objects, signs and people across regions and intercontinental space" (Held et al. 1999) in which, culture, as an accumulation of human acts which are deepening, widening and speeding up the interconnection among people in all aspects of social life, has been stressed.

This connection, apparently, must be understood as the initial point linking economy and culture from which, Jameson (1998) pointed out that the fusion of those two elements could be a sign of globalisation. Through the emergence of new media which fosters the reception of cultural and economic information on the global scale, the transformation of the economic value to the cultural value manifested by the increase of consumerism and the popularisation process of mass culture through the mass market, globalisation has gradually extended its range. This idea has made possible for the statement that globalisation could entail the cultural homogenisation as mass market, depicted by Richard Volkman (2006), would be the genesis of that process:

In a mass market, producers differentiate products through the pricing power of economies of scale. In order to achieve economies of scale, producers standardise their products. The results are cheap products that are just good enough for most consumers. The "mass" in mass markets refers to the attributes of consumers, who are treated as a single, undifferentiated mass. While mass production reduces prices, it results in one-size-fits-all products. This is the very stuff of homogenisation. 
Ngo Van Tao (2011), who is under the influence of Jean Baudrillard also indicated that the mass culture, in which America could be seen as the representative, also makes people sink into a postmodern mentality which seems to demonstrate a sense of assimilation. Accordingly, every artistic work would be examined under the eyes of investors instead of aesthetical souls. Cultural products, as stated by Ngo (2011), because of their identical nature, "silently wait for being evaluated and transferred with an acceptable price." People, thus, is easy-going to sit in the sofa, enjoy a TV series which is a combination of sex, action, pathetic acts instead of realising what could be the trustworthy motion picture; searching for themselves in a noisy but empty field consisting of contingent sound. Looking from this viewpoint, cultural homogenisation is not only perceived as the way that Americanisation has taken place as stated by Jameson, but it is also a process of reification in which, the loss of national culture begins with the altered attitude of people who easily accept their individuals to mingle with the others.

Nonetheless, it would raise a contentious discussion if we simply give a nod of approval that cultural homogenisation is an inherent product given birth by globalisation. This acceptance, simultaneously, paves the pathway for the idea that Americanisation and the urban capitalism, by default, is the archetype of globalisation; thus, globalisation seems to become another ethnocentric perspective in the contemporary era in which, the United States plays the supreme role. This idea, evidently, could not be seen as a wise statement as it also annihilates the role as well as the position of other nations who also participate in the global context of spreading cultural influence. Mittelman (2001: 7), one of the pioneers in researching globalisation, did remind us that "globalisation is not a single, unified process but a set of interactions that maybe best approached from different observations points." Therefore, the interaction of globalisation upon culture should be reconsidered as it would be insufficient if the whole process of globalisation, intentionally, has been unified with a pattern of hegemony.

Tran Huu Dung (2015) as well as Gertrude Himmelfarb (2001) suggested that the mass culture has conquered the personal tendency of audiences with which, things that other countries could receive are results of massive production which already lost their own aura - the genuine and authenticity usually found in dogmatic, classical and elite culture as stated by Walter Benjamin (2006: 58 ). Thus, the accusation given to globalisation could not only be placed on the exogenous value but we must also examine the selection of individual/ personal taste. This taste has not only been ruined, as indicated by Ngo Van Tao (2011) as well as Adorno and Horkheimer (1944) (cited by Ngo Van Tao 
2011), by a singular unit but other participation as Korean Wave in the 90s or the influence of Japanese culture could also be counted in. George Ritzer (1998: 68) presented an ostensibly bleak view that the lower classes - "are the ones who are most likely to go to McDonaldised schools, live in inexpensive, massproduced tract houses and work in McDonaldised jobs." Those classes have been chained with "an increase in efficiency, predictability, calculability and control through the substitution of non-human for human technology" (Ritzer 1998: vii) that the United States is the "criminal" but in fact, as analysed, the United States is not alone in the whole process. Vietnam and its cognitive procedure of Celebrities could be cited as an example.

After the fallout of the Soviet Union along with the reconciliation happened in Germany, the presence of Russian and East German celebrities in the everyday life of Vietnam became less prominent and seemed to become retrospective. Vietnam seems to be extreme in receiving Hollywood characteristics as those film stars are less influential in spreading the American image. Instead, various Asian celebrities admired in Vietnam have the advantage as they could be viewed as cultural representatives who partly describe their cultural identification. In Vietnam, the media has been inclining toward the Vietnamese, Chinese and Korean celebrities as the three "hot" zones that they can lure the audience with plenty of information on those famous names. Tran (2008: 6) confirmed that "with a historical connection, the attention to Chinese media products becomes natural." During the Vietnam War, Tran (2009) indicated that Chinese martial art-themed novels appeared on a regular basis in newspapers and literature magazines of Southern Vietnam where the majority of Chinese Vietnamese live. Although being influenced by the Culture Revolution in China during the 70s that made the communist state list this genre as heart-corrupting cultural products as well as the tension between two countries after the border struggle in 1979, the penetration of this genre along with Hong Kong drama in VHS tapes continued to rise as an undergrounded stream. When the diplomatic relationship was normalised in the late $80 \mathrm{~s}$, the intrusion of Chinese cultural products was then unavoidable (Ge 2017). The predestined relation between the two countries has built the pathway for the Chinese martial arts (wu xia), detective literature and motion picture to enter the Vietnamese people's mind. As a result, Chinese celebrities become more "near and dear" and "familiar," although the hatred attitude towards China is still brought out as an unsolvable issue (Nguyen 2011) since the two countries have taken part in the disputation over the maritime zone for such a long time and it does not signal any sign of ceasing. 
In case of Korean celebrities, the Korean Wave also hits this country, entailing remarkable harmonic sounds. This wave is defined as "the significant increase in the popularity of South Korean entertainment and culture starting in the 1990s" in Asia, and more recently in other parts of the world (Ravina 2009: 3). It represents a surge in the international availability of Korean culture, and Vietnam did not stand on the marginal side, not to mention that it engages with it actively more than ever (which is not an easy task, especially in the central region of Vietnam where South Korean army swept out and organised numerous raids and massacres during Vietnam War, the wound is in fact not easy to be healed and old people still blame young generations for being ignorant. ${ }^{2}$ However, the presence and expansion of Korean culture are undeniable). The Korean images reflected through movies and music video clips have sketched a canvas of "glistening" beauties which almost receive the interference of cosmetic surgery (Son Ha 2011), dream-like love stories, loose lyrics and catchy melodies as well as the uptown trend of fashion. The influence indeed has rapidly approached the youth and invisibly become a norm of suitability in not only the urban area but also in the rural region. In a more extreme situation, Co Tu people who are an ethnic minority group living in the mountainous area of Central Vietnam even tried to name their children after Korean Celebrities. This phenomenon even makes Vietnamese scholarswho mainly are nationalists, not feel at ease as they have to try to alert the State, stating that by naming children after Korean stars, Co Tu people are gradually assimilated by an alien flow of culture (Hua 2009).

The position consists of both superior, magnificent but also mundane is for Hollywood stars. For the southern part of Vietnam, its long-term attachment to the Americans might make the Whites appearance not a strange thing. Nevertheless, before Bern Agreement signed by Vietnam in 2004, the image of non-communist American/Western celebrities was only known through limited channels: music via fragmented television shows or radio programmes which provide videos or audio files from pirated foreign sources. Movies were not imported legally and were normally circulated via self-produced VHS tapes or DVDs dubbed in Vietnamese language by overseas Vietnamese or some uncredited amateurs. A brighter scenario was that movies aired by national TV but with an unstable frequency while the prime time was mainly occupied by telenovelas, Chinese or Korean series. Another channel that helped increase the exposure to American programmes was cable TV, which was introduced and popularised in Vietnam in 2001; but in the beginning, no Vietnamese subtitles were provided while the English proficiency of the Vietnamese audience was low at that time. Thus, the experience with cable 
TV programmes was mainly visual and totally lacked full understanding. Last but not least, the Internet as the platform to retrieve more information and services only rapidly developed after 1997 when it became a paid service that could be offered to the mass.

Critically, Americans are not Asians; therefore, their discourse is about the "others" who are distant from a Far East country. Vietnamese people, therefore, are most comfortable when they access the private information about these stars. On the one hand, because they are "someone else who is the foreigner" so they do not find guilty when peeping through the hole; on the other hands, the system of tabloids in the Western world has emerged for a long time that the information about the Celebrities is not only enough but even residual. The leakage of information subsequently becomes a matter of time only.

Therefore, the story of globalisation does not inherently belong to the United States and the cultural homogenisation is also a frivolous notion as other differences still occur as, in my opinion, other participants who equally have the right to join the playground of globalisation.

Moreover, as commented by Huntington (2000: 33), some states can choose to trace back the trail of the West and "its values and institutions." However, other states choose isolation at a high cost to themselves, and still, others have been attempting to modernise by their own method instead of Westernising. Differences, in this case, tend to become various endeavours to emerge and develop without being embraced by the shadow of the Western in general and the United States in particular. China, Myanmar, North Korea or Vietnam could be listed here as typical examples. On the one hand, they want to leave the low ranked image of being less advanced economy; on the other hand, they predict that the emulation of the western dominant capitalistic economy and military as suggested by Huntington (2000: 32) only produces a flaw version of rationality which is inherently not suitable for, in this case, Asian countries who seem to be ideological. Consequently, the imitation of development pattern only leads those states to the human degradation sooner because of the inappropriate nature. Therefore, it is understandable when the government in East Asian countries like China or Vietnam usually gives mottos or slogans highlighting the preservation of national pattern in sustainable development. On the one side, it is a manifestation of nationalism; on another side, it is a way to remind people that the portal to modernisation is not unique and alternative adequate options are still available.

To sum up, globalisation may be seen both as a process and a condition expressed in various dimensions. This process, indeed, is an unavoidable 
phenomenon which takes place daily with different trajectories for different regions. Instead of deducing that this process is trying to gather all aspects of human life into a homogenised source as a force of annihilation as well as unification, my mind aims to the idea that globalisation opens up various ways out for people to exchange values and elaborate current conditions through local methods. The hidden risk of cultural homogeneity, in fact, could only happen if the cognitive objects accept to lose themselves. Nevertheless, cultural resistance, in my thought, seems to be a congenital ability as people, although they could adapt with new cultural context flexibly, it does not mean they select the path of losing their national base. Cultural homogenisation, thus, with an optimistic viewpoint, would be a notion which shrinks to the size of a danger needed to be avoided rather than a catastrophic reality.

\section{THE CELEBRITY CONCEPT SEEN IN THE CASE OF A CHANGING VIETNAM}

The intentional presence of a famous person by providing a sequence of images surrounding his/her everyday life is apparently a clear example of what Daniel Boorstin believed. It could be explained by using the framing theory applied in mass media which helps mind-shape the audience. Erving Goffman (1974: 21) reminded us that frame in media is the "schemata of interpretation," with which we human could "locate, perceive, identify, and label a seemingly infinite number of concrete occurrences." This framing progress could be comprehended as a way to organise experiences and find out their meanings by consulting a referential system of knowledge or stereotype. That means, in order to understand a social phenomenon, people need to collect their universal but familiar value system such as symbols, myths, customs, etc., and make a fusion with provided images to provide an appropriate answer.

The media in Vietnam, especially online newspapers which own a huge number of readers such as Dan Tri (dantri.com.vn), VnExpress (vnexpress. net), Thanh Nien (thanhnien.com.vn) or media corporations who both have online newspaper and broadcasting channel such as Vietnamnet (vietnamnet. vn) and VTC (vtc.vn) always assume that images about a famous people are only different angles of exact reflection realised by the photographer to provide the audience with a true portrait of a person who used to be paid attention. The fact that paparazzi still exists could be a typical evidence of this statement. Williams Gamson, unfortunately, does not agree with it when he (1985: 618) pointed out that: 
News frames are almost entirely implicit and taken for granted. They do not appear to either journalists or audience as social constructions but as primary attributes of events that reporters are merely reflecting. News frames make the world look natural. They determine what is selected, what is excluded, what is emphasized. In short, news presents a packaged world.

According to him, the celebrity as a cognitive product has been kneaded subjectively by the media with a procedure consisting of selection and salience (Robert Entman 1993: 52). The reality of a person has been transformed to make the audience eager to know more about him by skilfully putting this reality into an order of prominence, with which it could create a matrix of moral evaluation, explanation, hypotheses or even a new description for a stranger. Especially, media bodies in Vietnam used to be a representative of a governmental body; for instance, Dan Tri Online is the voice of Vietnam Association for Promoting Education, Thanh Nien Online is the mouthpiece of Vietnam National Youth Union, while Vietnamnet is a sub-administration of Ministry of Information and Communication. Information provided by these bodies, thus, is by default considered official while it is not uncommon to see that news on Celebrity could almost be found nowhere but from this source. The accumulation of numerous images bared in people's mind becomes the context to produce the unconditional reaction and makes the audience get acquainted and familiar with the appearance of a specific person. Celebrities could receive their Fame with one kind of talents as an initial positive point, now possibly gains a higher level of being well-known through an addition of binary (good and bad) reputation even built from things which are not relevant to their will from the very beginning. This idea concurs with the comment of Messaris and Abraham (2001: 215) that whatever could change the audience's perception, it could definitely change the last result of the whole framing process. The Vietnamese media have rerouted the audience's focus from the core reason of getting famous (through having talent as mentioned above) to other trivial, temporary and even negative facets of a celebrity's life to nail in the audience's mind enormous information about him/her. More extremely, using celebrity as a way to endorse the news could go beyond imagination when sometimes, only the name of a celebrity shown in the title while the article's content does not contain any information which could trace back to this person. Moreover, while transcribing the interview content with a celebrity, reporters also try to deduce and interpret words following a direction that could make the content look more salient; and even mislead readers by making up a new story which is irrelevant. ${ }^{3}$ However, the Fame is more successfully achieved. 
A fascinating point to ponder on the media's writing on celebrities is about the two sides of the coin: the privacy and the publicness. Both reporters and the crowd are fond of the privacy, secrets, confidentiality and surprises (such as an adultery affair, a (un)intentional nudity, a paparazzi's photo, to name but a few) but the publicness (such as a nomination, an award, a good acting or a good performance which is paid attention by the press) expresses its own role in compiling the discourse of reputation. It was like an alibi for both celebrities and the public dealing with the violation of ethical standards or code of conduct. Nguyen (2011) continued by stating that "capitalism uses the media to make celebrities become a kind of commodities." That means, it sells their appearance and presence as much as possible; even exploits their individual life unforgivably to gain benefits without regret of its rudeness. Because the celebrities explicitly possess the publicness, it could alleviate the crowd's burden of morality found in their engagement with the personal life (of celebrities). Meanwhile, the celebrities have the right to reasonably think that the display of their private life or the exposure of their body (some naked photos or a sex tape, for example) in the mass media is acceptable because their identity no longer belongs to them personally; they are "a personality of the public."

John Harley (cited by Nguyen 2011) asserted that the celebrities appear due to "the excessive production of image leading to a face and body which are more easily identified." According to Leo Braudy (1986, cited by Graeme Turner 2004: 10), the fame is not a recent phenomenon. However, people believe that what we are witnessing today is not only the emergence of a quantitative tradition but also a qualitative change in the communication. One of the key conditions of the modern era to support the popularisation process is the new media, especially the Internet. Martin Lister (2009: 165) agreed that "the rapid spread of networked communication through PCs and servers has attracted enormous quantities of popular excitement, critical attention and commercial interest." The Internet is the aquatic environment while the celebrities are fish. The Internet is one of the postmodern conditions for celebrities that is capable of accommodating infinite information, its non-recurring nature, non-linear characteristic, as well as its anonymity-making process and the customisation of reception behaviour of the mass.

Intriguingly, the topic of the celebrities could become a source of attraction which gathers people around, especially in the urban area. In the transition from the rural land to the urbanism, it also creates the transformation of communication which changes the inter-individual linkage to the indirect conjunction using medium and digital devices. Louis Wirth (1938: 12) gave 
his argument that "the city is characterised by secondary rather than primary contacts." To explain this opinion, he (1938: 13-14) stated:

In a community composed of a large number of individuals than can know one another intimately and can be assembled in one spot, it becomes necessary to communicate through mediums and to articulate individual interest by a process of delegation.

More specifically, as Vietnam is cited as an example, in the pre-mass media culture in the rural area, individuals locate their social existence by talking with neighbours, relatives, children and grandchildren. Thanks to their direct connections, they know that they belong to a determined community of information because they all know the same thing that occurs in their everyday life. The topics are numerous pieces of news surrounding their ordinary life: rumour, scandal, worry, etc. of an individual who belongs to this closed and fixed sphere. Thus, the scale of the conversation and transmitted message is limited within this community's area/region. When they change their lives to integrate into the urban space, it is difficult for them to locate the existence of their social status. Within the area where they live or work, they are common discrete individuals who do not share the same homeland, kinship and cannot start a conversation without an initial point. Behind the locked doors of their condos and apartments, they have to trust and depend on the mass media with which they could recognise their existence by being a member of a certain information community. The aforementioned topics are now changed to a larger scale with the celebrities as the core and their lives as the peripheries: they talk about famous people and consider them the link to maintain the mutuality.

Michel Foucault provided a clear definition of discourse: "an entity of sequences of signs in that they are enouncements" (1969: 141). In this case, these signs lie in the demarcation line between the polished appearance and the trivial reality of celebrity, which subsequently help us understand them by reading them as a discourse. Indeed, on the one hand, Nguyen (2011) depicted that "the celebrities [in Vietnam] are unrealistic because their existence does not seem real, they are merely a myriad of incremental public images." On the other hand, they are inherently normal and plain. They also have a security number, a birth license, and have to cope with a myriad of forms of ordinary life's issues that human being could face. The two-sided ambiguity thus rises, making everything either possible or acceptable. A celebrity can opt for a number ways of personalising and polishing their appearance: (1) being 
gorgeous on the red carpet; or (2) try to create a scandal, through which they become the bullseye of the showbiz. At the same time, yet they could be caught while going shopping in a supermarket covered by an outfit that could easily mingle with the crowd. Their privacy becomes the property of the Others, and their life is no longer a single one because it is targeted, commented, scornfully talked or even insulted, although the crowd - those who are responsible for that intervention, is actually not supposed to get involved. Nhi T. Lieu (2013) noted that many Vietnamese people believe that beauty pageants provide opportunities for young women to take on social roles as cultural bearers, and thus pageant contests in Vietnam or even within the overseas Vietnamese diaspora play a crucial role in building up the national image. Articles with titles such as "Miss A does not make-up when going out" or "Miss B failed the university entrance exam"4 only make the public more penetrate into the ambiguity of meaning. Surprisingly, like a firefly, yet they more infatuate with this "bright world" which includes both the "normality" and "triviality" of plain life and are more curious about what happens behind the scene, although that scene is of someone who is totally a stranger.

\section{CELEBRITY - A TENTATIVE PERCEPTION MODEL}

In order to re-conceptualise the notion of celebrity in a changing world, I have tried to generalise a scheme of concepts which could thoroughly depict all features of celebrities seems to be by generating a perception model - a visual summary of what I tried to analyse as mentioned above.

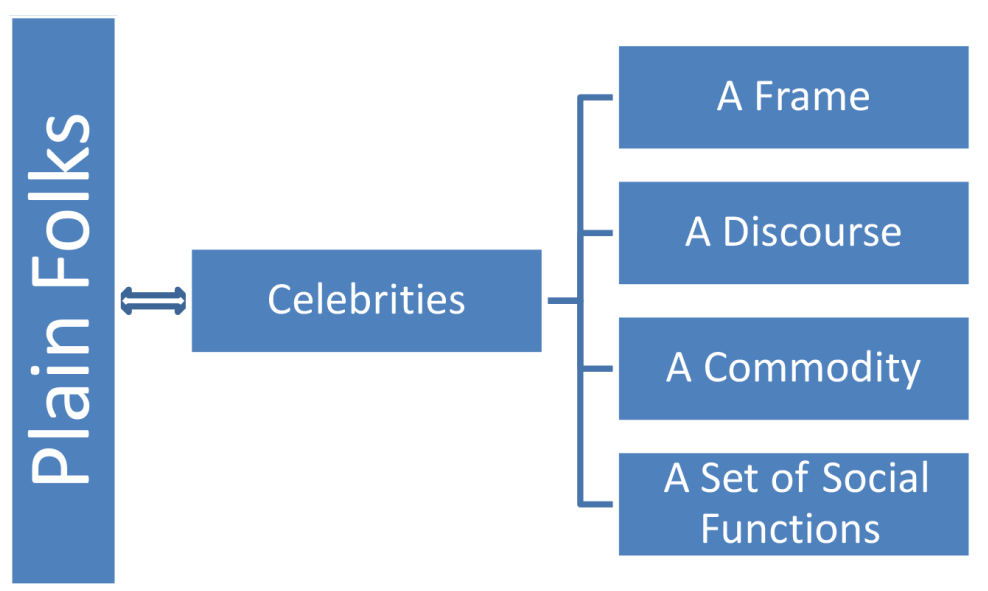

Figure 1: The concept model of Celebrities. 
The most salient characteristic of this model which guarantees its authenticity is the reciprocal relationship between the plain folks (the mass) and the celebrities. The celebrities could not be detached from the crowd because before becoming a personality, they are also members of one community; the mass is inherently their cradle of life before stepping out to the world. Even after they already climbed up to the peak of the hierarchy of reputation, yet they remain a voice in the ocean of Plain People because they cannot help but continue to live and experience a human being's life which is consisted of daily life routine, levels of emotion, major and minor upheavals, etc. If an unexpected event occurs which could eliminate their Fame or pull them down to the ground, they also come back to where they are from, keeping their existence as an ordinary individual like all other individuals out there. Moreover, plain folks create the environment and the context that emphasise and highlight the image of celebrities. The celebrities are famous when and only when they lie in the comparison relationship with the plain folks - those who become a referential system that determines the practical existence of the salience nature. In other words, if the celebrities just stand alone in the middle of no-oneness who can offer them various nuances of admiration, then the fame is inherently meaningless because its prominence nature is naturally annihilated: there is no equiponderance.

In contrast, normal people who help form the mass consider the celebrities a role model, a type of idol which is worth admiring and targeting. The fame becomes their goal, making them feel that they could escape from a flat surface, even a shallow one to rise and stand out to achieve a higher normative status, and becoming a frog who can jump out from the pond while the others still get stuck in a swamp filled with a lot of species who always want to know how the sunshine looks like, let's say with a rich style of images. The celebrities' life, as dissected, also becomes a part of their life - a society of the spectacle as suggested by Guy Debord (2002), in which people tend to know and sympathise more with totally strange and alien famous people who are absolutely distant from them while just a minor details of their neighbours per se is undoubtedly ignored. The duality of modern society is about atomising plain folks' life to a manageable size of nuclear families in which everything happens behind the walls and fences, even people who live right next door are not of their concern; and magnifying it simultaneously since communication in general and mass new media particularly help the folks to get involved with all events dynamically taking place outside with celebrity is the central point. 


\section{CONCLUSION}

From my viewpoint, revolutionary mass media, visual satisfaction and the demand of the consumers constitute the context for the emergence of communication in modern life seen in the context of globalisation. Within the boundaries of the mentioned entities, the story on the celebrities seems to be a non-stop and endless one. Obviously, as long as an individual still wants to be well known by the others, yet the spiral of the fame remains the subject of the mass media, which resonates with a way that David Marshall (1997: 65) suggested: "Celebrities represent subject positions that audiences can adopt or adapt in their formation of social identities." Understanding them either by looking through Cultural Studies lens or using a perception model, both are ways to "devitalise their 'charisma' and delusion" (Turner 2004: 127). To communist countries, with Vietnam is a representative, the reception of foreign well-known person set a milestone in the process of getting closer to the outside world and accepting capitalistic cultural products, although administrative bodies are still "haunted" by a sceptical attitude. Since the economy in Vietnam has been market-oriented since 1986, this acceptance also makes communism in this country a gentler version.

\section{ACKNOWLEDGEMENTS}

This research was supported by National University of Singapore (NUS) Research Scholarship granted by NUS, Singapore. The author thanks Dr. Nguyen Thu Giang of University of Pennsylvania, United States who provided insight and expertise that greatly assisted the research.

\section{NOTES}

* Phan Quang Anh is a PhD candidate in Department of Communications and New Media, National University of Singapore. He holds a master's degree in Cultural and Critical Studies from University of Westminster, United Kingdom. His published papers mainly focus on topics of game studies, media studies and Southeast Asian studies.

1 Lady Gaga could be a typical example. When she initiated her first steps on the avenue of Fame in the music industry, she was invited to sing at the Miss Universe Pageant Contest hosted in Vietnam in 2008. No one in Vietnam paid attention to her as a Celebrity at that time. Indeed, they only knew about her as a foreign singer. Only until media has continuously written about her "weird" fashion and she has become famous, then Vietnamese people recognise her as a Celebrity. See Thanh Pham (2012). 
2 This issue has recently been brought up when young Vietnamese people used an app on Facebook to help them capture pictures in which they could dress Korean military uniform that make them look like actors in the well-known Korean series Descendants of the Sun starring Song Hye Kyo and Song Joong-ki. A number of related articles could be found via this link: http://petrotimes.vn/tags/hau-due-mat-troi.tag

3 This phenomenon has been spreading out to the level that the government had to interfere. The proof of this intervention could be found back to 2010 and 2011 when Vietnam National Television (a broadcasting system of the government) must bring to stage a comedy on New Year's Eve to "gently" criticise this issue. With a communist country like Vietnam, using the national channel on this occasion to criticise has the same meaning as an official warning. See Tu Yen (2010) and Khanh Linh (2012).

4 Topics on Education are paid great attention by Vietnamese media when they have to deal with Celebrities. Common enquiries such as: did they really graduate, are their academic transcripts impressive, did they study abroad, etc. are usually found in articles' title. Using Google as the search engine and keywords as "Vietnam Media" and "Educational Qualification of Celebrity," 2,840,000 results are provided. Miss Vietnam 2008 Thuy Dung who failed the high school diploma examination or a number of beauty contestants who cannot speak English fluently can be seen as a typical example. It is understandable when Vietnam has been under the Confucianism influence, in which education, knowledge and degrees are emphasised.

\section{REFERENCES}

Baudrillard, J. 2010. Simulacra and simulation. Michigan: University of Michigan Press. Benjamin, W. 2006. Protocols of drug experiments. In On Hashish, trans. Eiland, H. et al., 1-12. Cambridge: MIT Press.

Boorstin, D. 1982. The image: A guide to pseudo-events in America. New York: Atheneum. Debord, G. 2002. The society of the spectacle. Canberra: Treason Press.

Griswold, W. 1994. Cultures and society in a changing world. London: Pine Forge Press.

Entman, R. 1993. Framing: Toward clarification of a fractured paradigm. Journal of Communication 43 (4): 51-58, https://doi.org/10.1111/j.1460-2466.1993.tb01304.x.

Foucault, M. 1969. The archeology of knowledge. Paris: Editions Gallimard.

Gamson, W. A. 1985. Goffman's legacy to political sociology. Theory and Society 14 (5): 605-622, https://doi.org/10.1007/BF00160018.

Ge, S. S. 2017. The influence of Chinese culture on television to young people in Vietnam. Master diss., VNU University of Social Sciences and Humanities, Vietnam.

Goffman, E. 1974. Frame analysis: An essay on the organization of experience. New York: Northeastern University Press.

Hartley, J. 2002. Communication, cultural and media studies: The key concepts. London: Routledge.

Held, D. et al. 1999. Global transformations: Politics, economics and culture. Stanford: Stanford University Press.

Himmelfarb, G. 2001. One nation, two cultures: A searching examination of American society in the aftermath of our Cultural Revolution. New York: Vintage. 
Hua, X. H. 2009. Co Tu People name their children after Korean actors. http://www. thanhnien.com.vn/chinh-tri-xa-hoi/nguoi-cotu-dat-ten-con-theo-kieu-hanquoc-420463.html (accessed 20 March 2017).

Huntington, S. P. 2000. The clash of civilizations? In Foreign Affairs, 72 (3); cited from The Globalization Reader, eds. Lechner, F. J. and Boli, J. Oxford: Blackwell Publishers.

Jameson, F. 1998. Notes on globalization as a philosophical issue. In The cultures of globalization, eds. Jameson, F. and Myoshi, M., 54-77. New York: Duke University Press.

Khanh Linh. 2012. Comedy on New Year's Eve criticise online newspapers. http://danviet. vn/30256p1c30/tao-quan-tet-tan-mao-da-xoay-bao-mang.htm (accessed 18 March 2017).

Kroeber, A. and Kluckhohn, C. 1952. Culture: A critical review of concepts and definitions. New York: Meridian Books.

Lister, M. 2009. New media: A critical introduction, 2nd ed. London: Routledge.

Lessa, I. 2006. Discursive struggles within social welfare: Restaging teen motherhood. British Journal of Social Work 36 (2): 283-298, https://doi.org/10.1093/bjsw/ bch256.

Marshall, D. P. 1997. Celebrity and power: Fame and contemporary culture. Minnesota: University of Minnesota Press.

Messaris, P. and Abraham, L. 2001. The role of images in framing news stories. In Framing public life, perspectives on media and our understanding of the social world, eds. Reese, S. D., Gandy, O. H. and Grant, A. E. London: Lawrence Erlbaum Associates Publishers.

Mittelman, J. H. 2001. Globalization: Captors and captives. In Capturing globalization, eds. Mittelman, J. H. and Othman, N., 1-16. London: Routledge.

Nguyen, B. Q. 2007. National identity: The original creativity of artists. Tia Sang. http://tiasang.com.vn/-van-hoa/ban-sac-dan-toc-sang-tao-doc-dao-cua-ca-nhannghe-si-1338 (accessed 5 November 2017).

Nguyen, T. G. 2011. Celebrity and its possible social functions. VNU Journal of Science: Social Sciences and Humanities 27 (3), https://js.vnu.edu.vn/SSH/article/view/1598.

Ngo, V. T. 2011. Jean Baudrillard and virtual society. http://www.gio-o.com/ NgoVanTaoJeanBaudrillardTHD.htm (accessed 15 April 2012).

Nhi T. Lieu. 2013. Beauty queens behaving badly: Gender, global competition, and the making of post-refugee neoliberal Vietnamese subjects. Frontiers: A Journal of Women Studies, 34 (1): 25-57, https://doi.org/10.5250/fronjwomestud.34.1.0025.

Rausch, J. A. 2011. The significance of nationalism for the spread of Communism to Vietnam and Cuba. Master diss., Virginia Polytechnic Institute and State University, United States.

Ravina, M. 2009. Introduction: Conceptualising the Korean Wave. Southeast Review of Asian Studies 31: 3-9.

Reid. A. 2010. Imperial Alchemy: Nationalism and political identity in Southeast Asia. Cambridge: Cambridge University Press.

Ritzer, G. 1998. The McDonaldization thesis. London: Sage Publications.

Sardar, Z. and Van Loon, B. 1994. Introducing cultural studies. New York: Totem Books. 
Son Ha. 2011. Eager for cosmetic surgery in South Korea. http://tuoitre.vn/Chinh-tri-xahoi/Song-khoe/463805/Cuong-phau-thuat-tham-my-o-Han-Quoc.html (accessed 28 April 2012).

Thanh Pham. 2012. Is Lady Gaga famous thanks to Miss Universe in Vietnam? http:// tuoitre.vn/Van-hoa-Giai-tri/470206/Lady-Gaga-noi-tieng-nho-cuoc-thi-Hoa-hauhoan-vu-tai-VN.html (accessed 26 April 2012).

Tran, H. D. 2005. Culture and globalisation: Seen from economics. http://www.viet-studies. info/THDung/VanHoa_ToanCauHoa_THDung.htm (accessed 22 November 2012).

Tran, L. H. T. 2009. On the Jin Yong phenomenon in Vietnam. http://khoavanhoc-ngonngu. edu.vn/home/index.php?option $=$ com_content\&view $=$ article \&id $=214 \% 3 \mathrm{Abc}-\mathrm{u}-$ tim-hiu-v-qhin-tng-kim-dungq-ti-vit-nam\&catid=64\%3Avn-hc-nc-ngoai-va-vnhc-so-sanh\&Itemid=108\&lang=vi (accessed 31 October 2017).

Tran, T. A. 2008. Cultural-historical matters perception from the angle of psychology. Culture and Arts Magazine 290, August.

Tran, Q. V. et al. 1998. The bases of Vietnamese culturology. Hanoi: Education Publishing House.

Turner, G. 2004. Understanding celebrity. New York: SAGE.

Tu Yen. 2010. Alert: Online Media uses Rag to get more views. http://www.thethaovanhoa. vn/132N20100613100127416T0/bao-dong-cac-trang-tin-online-giat-gan-caukhach.htm (accessed 28 October 2012).

Volkman, R. 2006. Dynamic traditions: Why globalization does not mean homogenization. http://biblioteca.clacso.edu.ar/ar/libros/raec/ethicomp5/docs/ htm_papers/68Volkman,\%20Richard.htm (accessed 22 November 2012).

Wirth, L. 1938. Urbanism as a way of life. America Journal of Sociology 44 (1): 1-24. 